\title{
Giant infiltrating intermuscular angiolipoma of the posterior axioappendicular region: gross and microscopic features
}

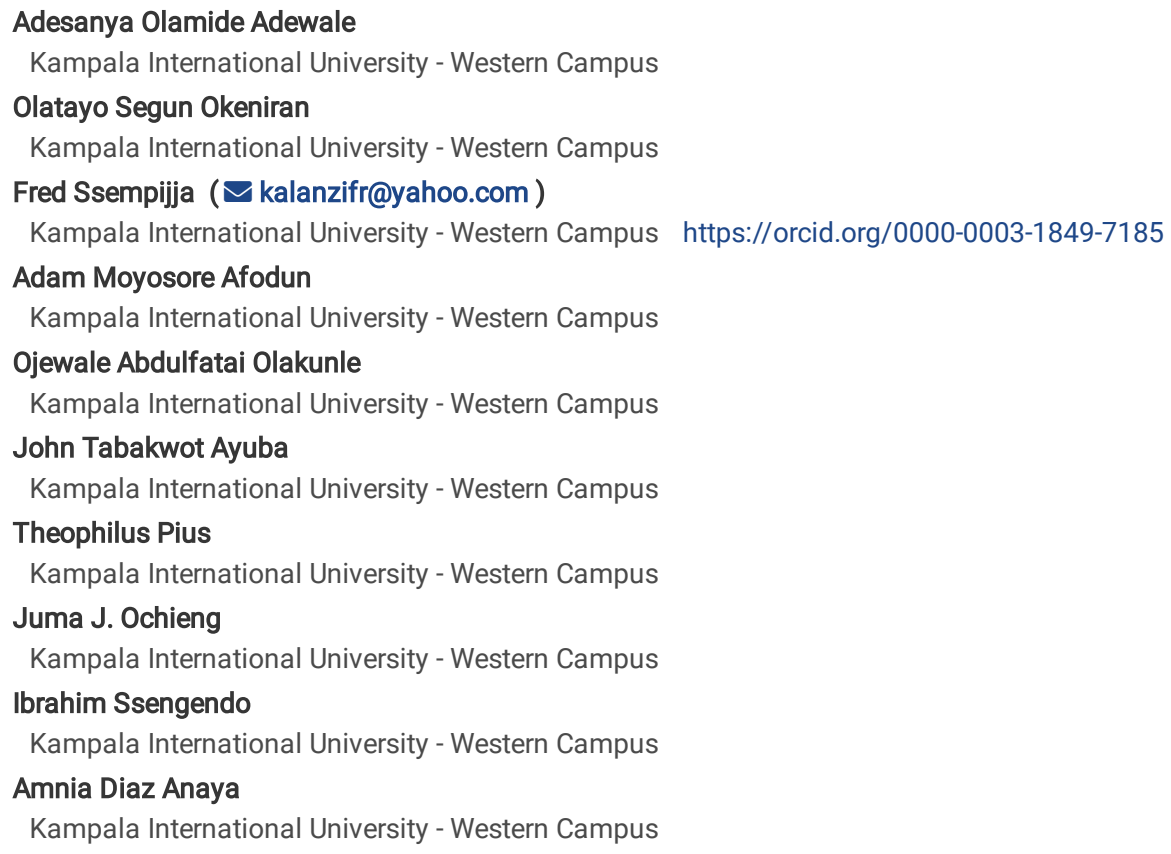

Keywords: Lipomatous tumor, Angiolipoma, infiltrating intermuscular angiolipoma, axioappendicular, cadaver, dorsal scapular blood vessels, trapezius muscle, rhomboid major muscle.

Posted Date: September 22nd, 2020

DOI: https://doi.org/10.21203/rs.3.rs-66912/v2

License: (1) This work is licensed under a Creative Commons Attribution 4.0 International License. Read Full License 


\section{Abstract}

Infiltrating intermuscular angiolipomas are rare. We report a cadaveric case of infiltrating angiolipoma in the muscles of the posterior axioappendicular region with literature in the context of live individuals. The macroscopic assessment showed a non-capsulated homogenous yellow mass was located between the trapezius muscle above and rhomboid major muscle below and invaded the dorsal scapular blood vessels from the rhomboid major muscle. It weighed 47.03 $\mathrm{g}, 8.5 \mathrm{~cm} \times 6.6 \mathrm{~cm} \times 1.7 \mathrm{~cm}$ (length, width, and thickness). Microscopic analysis shows mature fat cells, prominent blood vascular components, and no myxoid areas. Infiltrating intermuscular angiolipomas of the chest wall are very rare and to our knowledge, there is the scantiness of similar cases, hence we are providing an extra case of a giant infiltrating intermuscular angiolipoma of the posterior axioappendicular region, with particular emphasis on gross and microscopic features. In such cases, angiolipomas would require complete surgical excision to prevent continued growth, invasion, and recurrence.

\section{Background}

According to the 2002 and 2013 modified W.H.O (World Health Organization) bone and soft tissue tumor classification, lipomatous tumors are soft tissue tumors and are histologically subdivided into lipoma, lipomatosis, lipomatosis of nerve, lipoblastoma, angiolipoma, chondroid lipoma, myolipoma, spindle-cell lipoma, hibernoma, and dedifferentiated liposarcoma (Bancroft et al., 2006; Jo \& Fletcher, 2014; Laurence, 2004; Pernas et al., 2014). Angiolipoma is a subcutaneous nodule having mature adipocytes mixed with small vessels most of which having thrombi (Laurence, 2004). The W.H.O has classified angiolipomas as infiltrating or non-infiltrating types (Bancroft et al., 2006; Jo \& Fletcher, 2014; Laurence, 2004; Pernas et al., 2014). The infiltrating ones are very rare and partially or completely penetrate deep into the soft tissues mimicking aggressive tumors.

This study aims to report a cadaveric case of an infiltrating intermuscular angiolipoma of the posterior axioappendicular region with literature in the context of live individuals.

\section{Case Report}

\section{History and cadaveric information}

The samples were sourced from institutional cadavers during routine dissection of formalin fixed-cadavers in the Anatomy laboratory at Kampala International University, Western Campus located in Western Uganda. Although the patient's written informed consent was not applicable and we did not require documented consent for use of the specimen since this was a cadaveric case report performed on institutional cadavers, all ethical issues were considered in writing the case report e.g. the cadaver's identity, privacy, confidentiality, and permission were all maintained.

The Adipocytic specimen used was from a 45-year-old male Ugandan cadaver belonging to the ethnic group of Bantu peoples (Ankole tribe of western Uganda). Dissection was done by the usual dissection process using a method described by Cunningham (Koshi, 2017). The dissection and observations were carried out by at least three of the authors.

\section{Clinical findings}

During dissection of the posterior axioappendicular region, we noticed an unusual mass in the posterolateral axioappendicular region. On gross examination of the mass in situ, we identified a moderately soft mobile yellow mass that had infiltrated the soft tissues to be located between the trapezius muscle above it, and the rhomboid major muscle below (Figure 1A). Reflection of the tumor revealed an unencapsulated mass firmly adhered to the rhomboid major muscle, also we observed the mass to be completely encircling the dorsal scapular blood vessels that supply rhomboid major muscles (Figure 1B). After dissection, we excised the mass and it was seen as an unencapsulated lobulated homogenous yellow mass. The mass weighed $47.03 \mathrm{~g}$ and measured $8.5 \mathrm{~cm}$ long, $6.6 \mathrm{~cm}$ broad, and $1.7 \mathrm{~cm}$ thick (Figure 1C). This is an intermuscular mass. Due to its macroscopically big size (>2 cm in diameter) fatty appearance, being nonencapsulated, invasion of blood vessels, and its deep nature in between the muscles, it was tentatively diagnosed as a giant infiltrating intermuscular angiolipoma.

\section{Diagnostic assessment}

Microscopically the mass was composed of mature adipocytes with prominent blood supply (arterioles and venules), and lack of myxoid component. The components were arranged irregularly and mixed. These features were consistent with angiolipoma (Figure 2 A, B). Immunohistochemical study and molecular analysis were not performed. Confirmation of the mass as an angiolipoma histologically combined with its non-encapsulated nature, and its invasion of the soft tissues (e.g. intermuscular and angiogenic invasions), were consistent with an infiltrating intermuscular angiolipoma.

Figure 1: Gross features of a giant infiltrating intermuscular angiolipoma in a 45-year adult male cadaver. Dorsal view of the dissected superolateral posterior axioappendicular region: $\mathbf{A}=$ tumor in situ (I) between the reflected trapezius above $(\mathrm{t})$, and rhomboid major muscle beneath (R). $r=$ rhomboid minor muscle, imaginary features: dotted line = outline of medial border of the scapula, the black star * inferior angle of the scapula. This is an infiltrating intermuscular mass. $\mathbf{B}=$ reflected both rhomboid major muscle and adipocytic tissue $(\mathrm{I})$ showing prominent twig of a blood vessel (red star*) being circled by the mass, this is a continuation of the dorsal scapular vessels $(V)$. $F=$ deep fascia ensheathing rhomboid major muscle, $\mathrm{N}=$ dorsal scapular nerve, $\mathrm{S}=$ space normally occupied by rhomboid major muscle before being reflected. Note that the tumor is firmly attached to the muscle. $\mathbf{C}=$ post-dissection excised specimen (I) showing an unencapsulated yellow homogenous lobulated appearance, and size of mass $>2 \mathrm{~cm}$ in diameter. Findings are suggestive of a giant infiltrating intermuscular angiolipoma. 
Figure 2: Microscopic features of an angiolipoma in a 45-year adult male cadaver. $\mathrm{H} \& \mathrm{E}$ photomicrographs (transverse sections): $\mathrm{A}=\mathrm{x} 40, \mathrm{~B}=\mathrm{x} 100.1=$ mature fat cells, 2 = adipocyte nuclei, 3 = adipocyte cytoplasm, 4 = arterioles, 5 = venules, 6 = fibroblasts, 7 = arteriole lumens. Presence of prominent, vascular structures. These features depict mature adipose and proliferated vascular tissue consistent with an angiolipoma. Abbreviation: $\mathrm{H} \& \mathrm{E}=$ hematoxylin and eosin.

\section{Discussion}

According to the WHO classification of lipomatous tumors, the current case is an infiltrating angiolipoma which is an unusual type compared to the noninfiltrating one (Bancroft et al., 2006; Hagel et al., 2015; Jo \& Fletcher, 2014; Laurence, 2004; Pernas et al., 2014). A search for cases of intermuscular angiolipoma revealed only a limited number of documented cases in agreement with Arenaz et al. (Arenaz Búa et al., 2010). This infiltrating intermuscular angiolipoma had invaded deeper structures i.e. between muscles (trapezius and rhomboid major muscles), and encroaching on blood vessels (dorsal scapular blood vessels) in line with previous cases (Hagel et al., 2015; Rahman et al., 2009). Continued growth, invasiveness, and compression of blood vessels, nerves, and other soft tissues are encountered in infiltrating angiolipomas commonly leading to severe neuropathic, muscular, and joint pains (Shen et al., 2017; Yeo et al., 2018). Therefore, the most viable treatment option is the complete removal of the tumor surgically to avoid the continued growth, recurrence, and complications that are common with infiltrating angiolipomas (Orchis \& Ozonoff, 1986; Rahman et al., 2009; Shen et al., 2017; Yeo et al., 2018).

Similar to the current case, angiolipomas are the most prevalent type in the trunk and upper limbs compared to other lipomatous lesions (Altu \& Sahin, 2009; Yeo et al., 2018), however, it is unusual to find infiltrating angiolipomas in the posterior chest wall muscles (e.g. trapezius and rhomboid major for our case) since infiltrating angiolipomas occur mostly in the muscles of the lower limbs in $50 \%$ of the cases, and rarely in other places (upper limbs, $20 \%$; chest wall, 20\%; and other locations, 10\%) (Howard, W. R., \& HELWIG, 1960; Salvatore et al., 2003; Shen et al., 2017; Sheybani et al., 2016; Yeo et al., 2018). Finding the infiltrating angiolipoma in a 45-year-old man for the current case seems usual (most infiltrating angiolipomas occur in patients who are older than 30 years) (Arenaz Búa et al., 2010). However, age and sex are very variable factors in the occurrence of angiolipomas, e.g. some cases have shown no sex predominance and that the masses could occur in all age groups (Arenaz Búa et al., 2010).

By considering either the location of the mass or microscopic appearance, the major differential diagnoses of infiltrating intermuscular angiolipoma include soft-tissue angiomatosis, non-infiltrating angiolipoma, intramuscular angioma. Soft-tissue angiomatosis is the diffuse proliferation of benign vascular structures, associated with mature fat tissue, which involves a large segment of the body in a continuous pattern, histologically they contain clusters of thickwalled capillary-like vessels near veins, many endothelial cells in the vessels of soft tissue angiomatosis, intermingled with fat tissue in continuous tissue planes and usually with myxoid areas. Intramuscular angioma is located within a skeletal muscle with histopathological features being mature adipose tissue, blood component, and muscle tissue (Val-Bernal et al., 2005). Non-infiltrating angiolipomas are encapsulated and are located subcutaneously (Liu et al., 2016). Other differential diagnoses might be the deep intermuscular lipoma and infiltrating lipoma. The deep intermuscular lipoma is a benign tumor composed of mature adipose tissue and is intimately associated specific non-adipose (muscle) tissue similar to our case but histologically its fat tissue does not contain prominent blood vascular structure; infiltrating lipoma affects multiple tissues such as skin, subcutaneous tissue, muscle, bone, and histological analysis shows no prominent blood vasculature being intermingled in the adipocytic tissue (Bancroft et al., 2006). In conclusion, infiltrating intermuscular angiolipoma might mimic soft tissue angiomatosis, non-infiltrating angiolipoma, intramuscular angioma, especially if the lesion is large. Knowledge of the histological composition, the pattern of vascular component, and clinicopathological correlation are vital to prevent misdiagnosis. Furthermore, the diagnosis of 'infiltrating angiolipoma' is controversial, with some authors diagnosing them as intramuscular hemangiomas with fatty overgrowth, and infiltrating lipoma; and the above two forms could be continuous intermediate stages of the same lesion (Arenaz Búa et al., 2010; Bancroft et al., 2006).

Since the mass was obtained from a cadaver, we could not establish some of the patient's vital information associated with the swelling such as patient's symptoms, family and psychosocial history, medical history, etiology and risks, treatment history, interventions, prognosis, and follow-up. Additionally, the patient's written informed consent was not applicable since this was a cadaveric case report.

\section{Conclusions}

The infiltrating intermuscular angiolipomas of the chest wall are very rare and to our knowledge, there is the scantiness of similar cases in humans, hence we are providing an extra case of a giant infiltrating intermuscular angiolipoma of the posterior axioappendicular region, with particular emphasis on its gross and microscopic features. Although extremely rare, infiltrating intermuscular angiolipoma ought to be thought of as a differential diagnosis of chest wall lesions. In such cases, these angiolipomas would require complete surgical excision because infiltrating angiolipomas are invasive, with high rates of growth and recurrence. The good news is that surgical management of the lesion is associated with a good prognosis provided the tumor is completely excised.

\section{Declarations}

\section{Data Availability}

Not applicable

\section{Conflicts of Interest}

The authors declare that they have no competing interests.

\section{Funding Statement}


Not Applicable

\section{Ethical approval}

Ethical approval was acquired from the Scientific and Ethics review committee of Kampala International University Western Campus, Uganda (Nr.UG-REC03/202050).

\section{Consent}

The samples used were from cadavers sourced from institutional cadavers of Kampala International University, western campus, and did not necessitate documented consent for their donation, and informed consent of the patient did not apply since this was a cadaveric case study. But all the ethical issues were considered in writing the case report e.g. the cadaver's identity, privacy, confidentiality were all maintained and permission to use the cadaver for our study was obtained from the Department of Anatomy, Kampala International University, western campus.

\section{Authors' Contributions}

AOA, OSO, FS were the principal investigators of the study, dissected the cadaver, conducted the data collection, made the clinical diagnosis and report, and involved in drafting the article. AMA, TP, IS involved in drafting the article and involved in collection of the literature, JAT, JJO helped in manuscript drafting, and in the collection of the literature, ADA, OAO performed the pathological examination, wrote the report, and involved in drafting the article. All the authors approved the manuscript for publication and remain in agreement to be accountable for all aspects of the work. All the authors read and approved the final manuscript.

\section{Acknowledgments}

Permission was obtained from the Department of Anatomy, Kampala International University, western campus. Preclinical students of the University were present at the time of identifying the mass

\section{References}

Altu, H. A., \& Sahin, S. (2009). Non-infiltrating angiolipoma of the cheek: a case report and. 51(1), 137-139.

https://doi.org/https://doi.org/10.2334/josnusd.51.137

Arenaz Búa, J., Luáces, R., Lorenzo Franco, F., García-Rozado, Á., Crespo Escudero, J. L., Fonseca Capdevila, E., \& López-Cedrún, J. L. (2010). Angiolipoma in head and neck: report of two cases and review of the literature. International Journal of Oral and Maxillofacial Surgery, 39(6), 610-615.

https://doi.org/10.1016/j.ijom.2009.12.021

Bancroft, L. W., Kransdorf, M. J., Peterson, J. J., \& O’Connor, M. I. (2006). Benign fatty tumors: classification, clinical course, imaging appearance, and treatment. Skeletal Radiology, 35(10), 719-733. https://doi.org/10.1007/s00256-006-0189-y

Hagel, C., Goebell, E., Westphal, M., \& Saeger, W. (2015). Angiolipoma of the sellar region. Pituitary, 18(1), 176-178. https://doi.org/10.1007/s11102-014-0555z

Howard, W. R., \& HELWIG, E. B. (1960). Angiolipoma. Archives of Dermatology, 82(6), 924-931. https://doi.org/10.1001/archderm.1960.01580060078011

Jo, V. Y., \& Fletcher, C. D. M. (2014). WHO classification of soft tissue tumours: an update based on the 2013 (4th) edition. Pathology, 46(2), 95-104. https://doi.org/10.1097/PAT.0000000000000050

Koshi, R. (2017). Cunningham'S Manual of Practical Anatomy Uppwe and Lower Limbs 16Th Edition (K. Rachel (ed.); 16th ed., Vol. 1). Oxford University Press. https://books.google.co.ug/books?

$\mathrm{hl}=$ =n\&lr=\&id=slJZDwAAQBAJ\&oi=fnd\&pg=PP1\&dq=cunningham+manual+of+practical+anatomy+volume+one\&ots=MuaPVr1pvy\&sig=tsZVgaQW2ii_eNQTzL manual of practical anatomy volume one\&f=false

Laurence, M. (2004). Advances in Tissue Banking - Volume 6. The Journal of Bone and Joint Surgery. British Volume, 86-B(3), 466-466.

http://online.boneandjoint.org.uk/doi/10.1302/0301-620X.86B3.15416

Liu, P., Che, W.-C., Ji, H.-J., \& Jiang, Z.-M. (2016). A giant infiltrating angiolipoma of the mediastinum: a case report. Journal of Cardiothoracic Surgery, 11(1), 164. https://doi.org/10.1186/s13019-016-0560-6

Orchis, D. De, \& Ozonoff, M. B. (1986). Skeletal Radiology Infiltrating angiolipoma with phlebolith formation. https://doi.org/10.1007/BF00355107.

Pernas, R. O., González, R. P., \& Armentia, E. S. (2014). Benign soft-tissue lesions of the fingers: radiopathological correlation and clinical considerations. https://doi.org/10.1007/s00256-014-2040-1

Rahman, G., Abdulkadir, A., \& Yusuf, I. (2009). Lipomatous lesions around the shoulder: Recent experience in a Nigerian hospital. International Journal of Shoulder Surgery, 3(1), 13. https://doi.org/10.4103/0973-6042.50877 
Salvatore, C., Antonio, B., Vecchio, W. Del, Lanza, A., Tartaro, G., \& Giuseppe, C. (2003). Case Report Giant Infiltrating Lipoma of the Face: CT and MR Imaging Findings. February, 283-286.

Shen, G., Su, M., \& Kuang, A. (2017). I NTERESTING I MAGE PET / CT and MR Features of Infiltrating Spinal Angiolipoma. 44(3), 2018-2020. https://doi.org/10.1097/RLU.0000000000002410

Sheybani, E. F., Eutsler, E. P., \& Navarro, O. M. (2016). Fat-containing soft-tissue masses in children. Pediatric Radiology, 1760-1773. https://doi.org/10.1007/s00247-016-3690-z

Val-Bernal, J. F., Martino, M., Garces, C. M., \& Garijo, M. F. (2005). Soft-tissue angiomatosis in adulthood: A case in the forearm showing a prominent myxoid adipose tissue component mimicking liposarcoma. Pathology International, 55(3), 155-159. https://doi.org/10.1111/j.1440-1827.2005.01801.x

Yeo, E. D., Chung, B. M., Kim, E. J., \& Kim, W. T. (2018). Infiltrating angiolipoma of the foot: magnetic resonance imaging features and review of the literature. https://doi.org/10.1007/s00256-017-2870-8

\section{Figures}
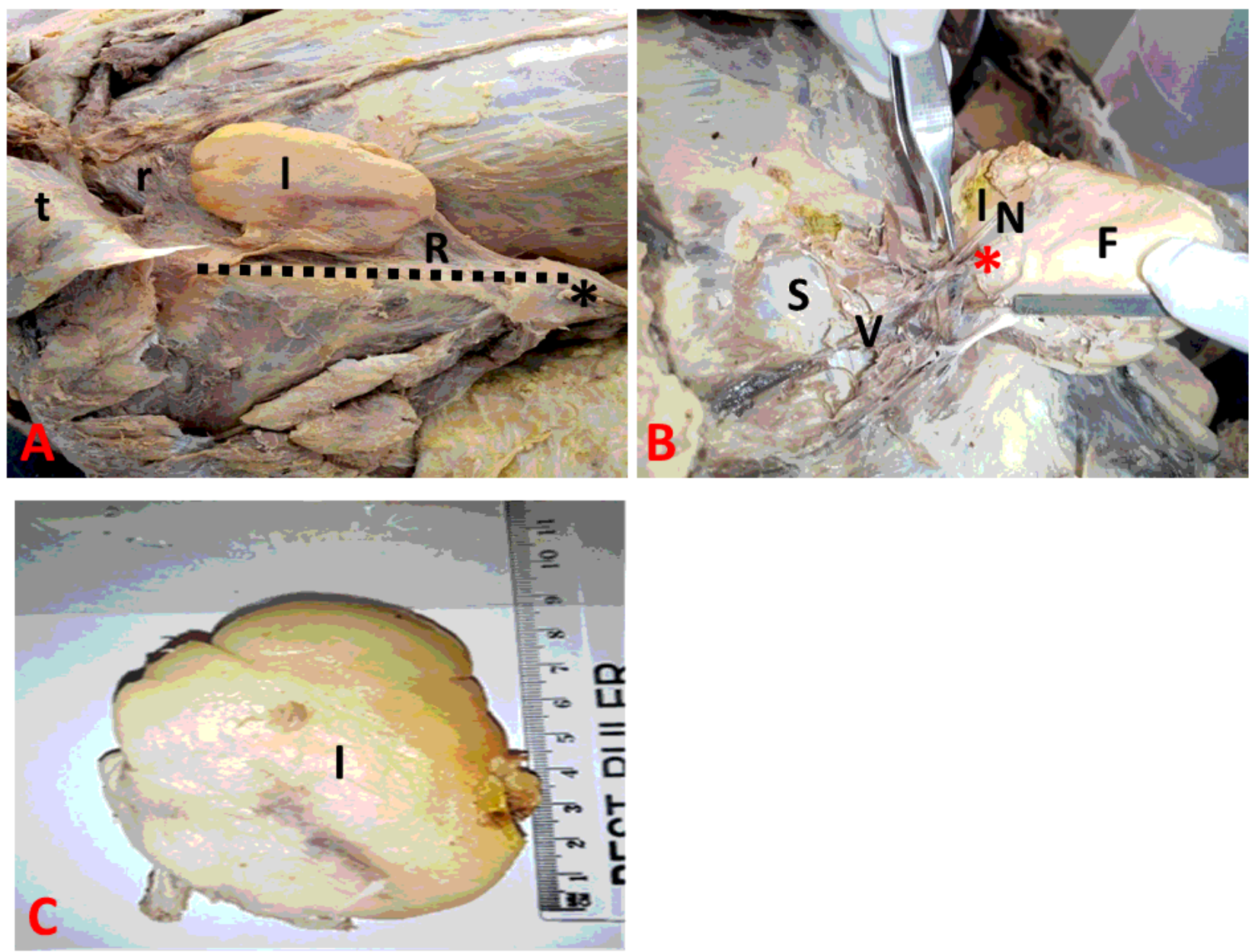

\section{Figure 1}

Gross features of a giant infiltrating intermuscular angiolipoma in a 45-year adult male cadaver. Dorsal view of the dissected superolateral posterior axioappendicular region: $A=$ tumor in situ (I) between the reflected trapezius above $(t)$, and rhomboid major muscle beneath $(R)$. $r=$ rhomboid minor muscle, imaginary features: dotted line = outline of medial border of the scapula, the black star * = inferior angle of the scapula. This is an infiltrating intermuscular mass. $B=$ reflected both rhomboid major muscle and adipocytic tissue (I) showing prominent twig of a blood vessel (red star*) being circled by the mass, this is a continuation of the dorsal scapular vessels $(V)$. $F=$ deep fascia ensheathing rhomboid major muscle, $N=$ dorsal scapular nerve, $S=$ space normally occupied by rhomboid major muscle before being reflected. Note that the tumor is firmly attached to the muscle. $\mathrm{C}=$ post-dissection excised specimen (I) showing an unencapsulated yellow homogenous lobulated appearance, and size of mass $>2 \mathrm{~cm}$ in diameter. Findings are suggestive of a giant infiltrating intermuscular angiolipoma. 

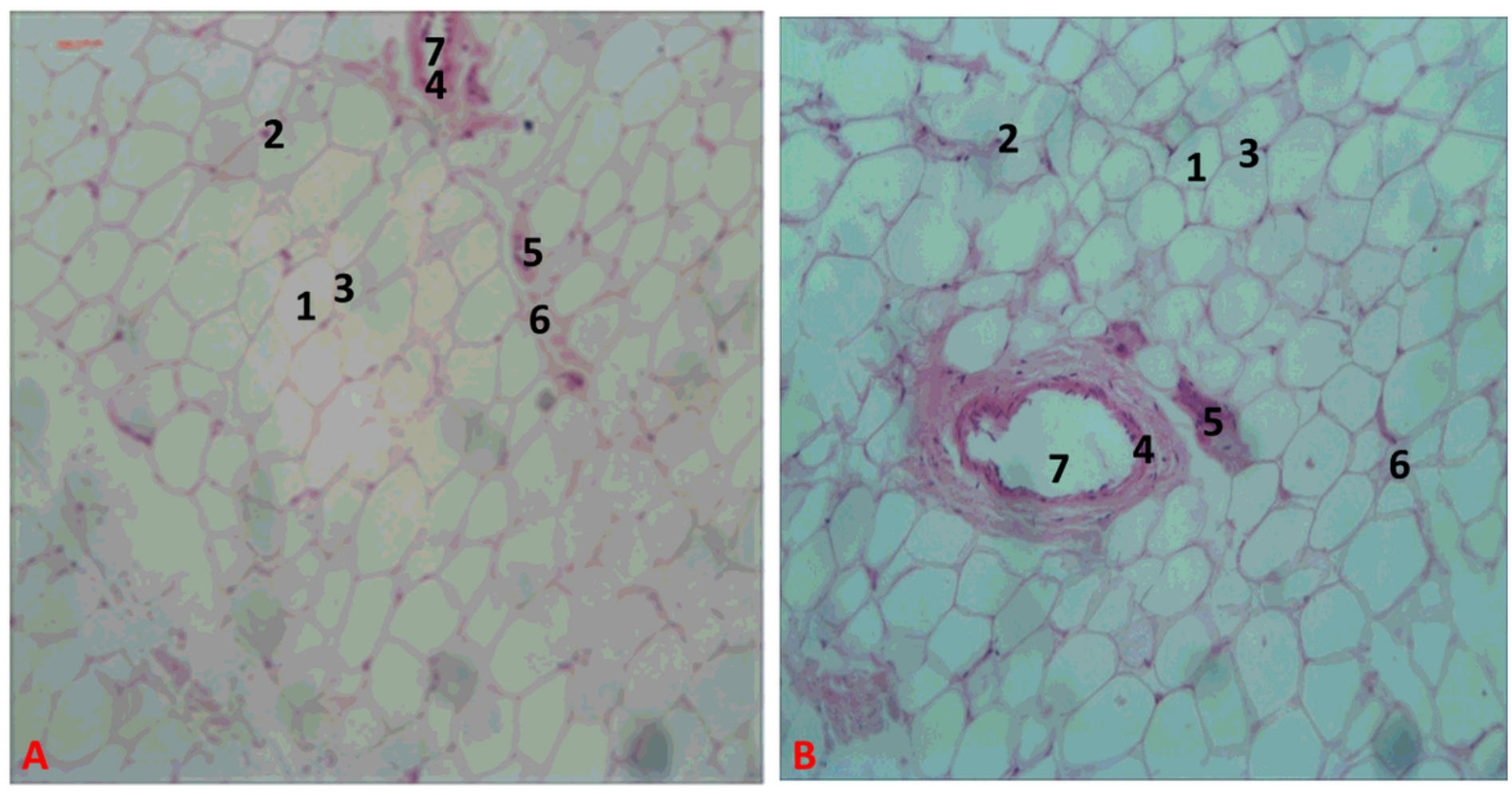

\section{Figure 2}

Figure 2: E photomicrographs (transverse sections): $\mathrm{A}=\mathrm{x} 40, \mathrm{~B}=\mathrm{x} 100.1=$ mature fat cells, $2=$ adipocyte nuclei, $3=$ adipocyte cytoplasm, $4=$ arterioles, $5=$ venules, 6 = fibroblasts, 7 = arteriole lumens. Presence of prominent, vascular structures. These features depict mature adipose and proliferated vascular tissue consistent with an angiolipoma. Abbreviation: $\mathrm{H} \& \mathrm{E}=$ hematoxylin and eosin. 